\title{
Landscape of Multidrug-Resistant Gram-Negative Infections in Egypt: Survey and Literature Review
}

\author{
Amani El-Kholy (D) \\ Hadir A El-Mahallawy (D) ${ }^{2}$ \\ Noha Elsharnouby ${ }^{3}$ \\ Mohamed Abdel Aziz ${ }^{4}$ \\ Ahmed Mohamed Helmy ${ }^{5}$ \\ Ramy Kotb ${ }^{6}$ \\ 'Department of Clinical Pathology, \\ Faculty of Medicine, Cairo University, \\ Cairo, Egypt; ${ }^{2}$ Clinical Pathology \\ Department, National Cancer Institute, \\ Cairo University, Cairo, Egypt; \\ ${ }^{3}$ Department of Anesthesia, Intensive \\ Care and Pain Management, Faculty of \\ Medicine, Ain Shams University, Cairo, \\ Egypt; ${ }^{4}$ Pfizer Egypt, Levant \& Iraq \\ Medical Affairs, Cairo, Egypt; ${ }^{5}$ Pfizer \\ Egypt Medical Affairs, Cairo, Egypt; \\ ${ }^{6}$ Pfizer Africa \& Middle East Medical \\ Affairs, Dubai, United Arab Emirates
}

\begin{abstract}
Purpose: This article is the first to review published reports on the prevalence of multidrugresistant (MDR) gram-negative infections in Egypt and gain insights into antimicrobial resistance (AMR) surveillance and susceptibility testing capabilities of Egyptian medical centers.

Materials and Methods: A literature review and online survey were conducted.

Results: The online survey and literature review reported high prevalence of extendedspectrum $\beta$-lactamase (ESBL)-producing Enterobacteriaceae (19-85.24\% of E. coli, and $10-87 \%$ of $K$. pneumoniae), carbapenem-resistant Enterobacteriaceae $(35-100 \%$ of K. pneumoniae and $13.8-100 \%$ of E. coli), carbapenem-resistant Acinetobacter baumannii (10-100\%), and carbapenem-resistant Pseudomonas aeruginosa (15-70\%) in Egypt. Risk factors for MDR Gram-negative infections were ventilated patients (67.4\%), prolonged hospitalization (53.5\%) and chronic disease (34.9\%). Although antimicrobial surveillance capabilities were deemed at least moderate in most centers, lack of access to rapid AMR diagnostics, lack of use of local epidemiological data in treatment decision-making, lack of antimicrobial stewardship (AMS) programs, and lack of risk prediction tools were commonly reported by respondents.

Conclusion: This survey has highlighted the presence of knowledge gaps as well as limitations in the surveillance and monitoring capabilities of AMR in Egypt, with most laboratories lacking rapid diagnostics and molecular testing. Future efforts in Egypt should focus on tackling these issues via nationwide initiatives, including understanding the AMR trends in the country, capacity building of laboratories and their staff to correctly and timely identify AMR, and introducing newer antimicrobials for targeting emerging resistance mechanisms in Gram-negative species.
\end{abstract}

Keywords: Egypt, Gram-negative bacteria, hospital-acquired pneumonia, intra-abdominal infections, multidrug resistance, urinary tract infections

\section{Introduction}

Gram-negative species are ubiquitous in nature and associated with a plethora of infections in different body sites. ${ }^{1}$ Gram-negative bacteria are intrinsically resistant to many antibiotics. ${ }^{2}$ Antimicrobial resistance (AMR) in Gram-negative bacteria has become increasingly problematic for healthcare systems over the past 20 years, with escalating costs and mortality. ${ }^{1}$ Gram-negative species are frequently associated with nosocomial infections, including bloodstream infections (BSI), hospitalacquired pneumonia (HAP), urinary tract infections (UTI), skin and soft-tissue infections (SSTI) and complicated intra-abdominal infections (cIAI). ${ }^{3,4}$

Resistance becomes particularly problematic when organisms become multidrug-resistant (MDR) or extensively drug-resistant (XDR) as physicians are then
Correspondence: Amani El-Kholy Department of Clinical Pathology, Faculty of Medicine, Cairo University, Cairo, Egypt

Tel +201001678063

Email aaakholy@gmail.com 
limited by the treatment options they can use. ${ }^{5}$ In addition to the increasing resistance to available treatments, concerns regarding the limited number of new treatments under development have also been raised. ${ }^{6}$ In response to these concerns, the World Health Organization (WHO) published the global priority list of antibiotic-resistant bacteria, identifying resistant species deemed to be the most significant globally, and for which there is an urgent requirement for new antimicrobials to be developed. ${ }^{7}$ Three Gram-negative species were deemed "critical" under priority-one: carbapenem-resistant Acinetobacter baumannii (CRAB), carbapenem-resistant Pseudomonas aeruginosa (CRPA), and carbapenem-resistant and thirdgeneration cephalosporin-resistant Enterobacteriaceae. ${ }^{7}$

As new classes of antibiotics have been developed, Gram-negative bacteria have gained resistance through a variety of $\beta$-lactamase enzymes: initially through penicillinases, then cephalosporinases, extended-spectrum $\beta$ lactamases (ESBLs) and carbapenemases. ${ }^{8}$ Carbapenem resistance can result from the production of carbapenemase enzymes, or the combined activity of ESBL and efflux pumps, or porin mutations. ${ }^{1}$ Both intrinsic and acquired carbapenem resistance has been observed in Gram-negative bacteria, with acquired resistance in Enterobacteriaceae being mainly plasmid-mediated leading to horizontal gene transfer. ${ }^{8}$ Carbapenems are highly effective broad-spectrum antibiotics; there is therefore an urgent need for carbapenem-sparing strategies to reduce the spread of multidrug resistance globally. ${ }^{9}$

Treatment of MDR Gram-negative infections requires high levels of clinical and microbiological expertise as well as knowledge of the local epidemiology and patient risk factors. ${ }^{10}$ Commonly used antimicrobial agents to treat MDR Gram-negative infections include colistin, aminoglycosides, tigecycline, carbapenems and Fosfomycin. ${ }^{10-15}$ Novel treatment options for MDR gramnegative infections include the $\beta$-lactam $/ \beta$-lactamase inhibitor (BL-BLI) combinations (ceftazidime-avibactam, meropenem-vaborbactam, ceftolozane-tazobactam and imipenem cilastatin relebactam), eravacycline and cefiderocol. ${ }^{10,16-19}$ Challenges in the treatment of MDR Gram-negative infections include the emergence of resistance to novel antimicrobials, such as ceftazidimeavibactam, ${ }^{20}$ meropenem-vaborbactam, ${ }^{21}$ ceftolozanetazobactam, ${ }^{22}$ and cefiderocol. ${ }^{23}$ Implementing restrictions on the overuse of these antibiotics is therefore required whilst ensuring early and appropriate treatment for critically ill patients. ${ }^{10}$ Further challenges include the ineffectiveness of newer agents against $\mathrm{CRAB}^{24}$ and the need for carbapenemase identification prior to BL-BLI treatment. ${ }^{10}$ There is growing complexity surrounding the treatment of MDR Gram-negative infections, with the necessity to understand both national and local epidemiology, how to provide adequate empiric coverage, and have sufficient surveillance to identify opportunities to treat bacteria with emerging resistance mechanisms with new agents.

\section{Aims}

This article aims to:

1. Review the prevalence of MDR Gram-negative infections in Egypt from published literature

2. Gain a better understanding of the epidemiology of MDR Gram-negative infections as well as AMR surveillance and susceptibility testing capabilities of medical centers in Egypt through an online survey

We focused on the WHO priority-one MDR Gramnegative pathogens. This is the first publication of its kind to summarize published data concerning the prevalence of MDR Gram-negative infections in Egypt and to obtain additional insights using a survey.

\section{Materials and Methods}

\section{Literature Search}

A literature search of publications reporting prevalence of MDR Gram-negative human infections in Egypt was performed. Publications were considered if they: included full-text articles with data concerning infections from medical or surgical units of hospitals in Egypt between 2004 and 2020, were written in English, included data concerning multidrug resistance, carbapenem resistance (or carbapenemase production) or third-generation cephalosporin-resistant (or extended-spectrum beta-lactamase production) in Enterobacteriaceae, Escherichia coli, Klebsiella pneumoniae, Acinetobacter baumannii or Pseudomonas aeruginosa and if they contained data concerning infections in humans. References within the publications were also screened for potential inclusion.

A MedLine database search was conducted through PubMed using the search string and filters: (Egypt[Text Word] OR Egyptian[Text Word]) AND (Gram-negative OR Gram negative OR Enterobacteriaceae OR 
Escherichia coli OR Klebsiella pneumoniae OR Acinetobacter baumannii OR Pseudomonas aeruginosa) AND (infection OR bacteria OR organism OR pathogen) AND (multidrug resistant OR multidrug-resistant OR multi-drug resistant OR MDR OR carbapenem resistance OR carbapenem-resistant OR carbapenemase OR extended-spectrum beta-lactamase OR ESBL OR thirdgeneration cephalosporin resistant OR MBL OR metallobeta-lactamase); filters: Full text, English, from 2004/ 1/1-2020/11/28; sorted by: First Author. The last search was conducted on the 28 November 2020. Titles and abstracts were first screened for inclusion, followed by a full-text review. Data was then extracted and tabulated for included publications.

\section{Online Survey}

The online survey was created using SurveyMonkey ${ }^{\circledR}$. Questions were generated to focus on the most common bacteria causing nosocomial infections, especially the WHO "critical" priority pathogens, ${ }^{7}$ and on the capabilities of centers across Egypt and the barriers they face. Questions were all closed-ended questions with yes/no or multiple- choice answers only to ensure reliability of the survey. Survey results were collected anonymously, with only center names and specialty collected for the participating physicians to encourage honest reporting of information.

Validity of the survey was established using published methodologies: ${ }^{25,26}$ firstly, the survey was reviewed on two levels, by a group of experts in antimicrobial resistance who evaluated if the survey questions sufficiently captured the topic of interest and by a medical communications agency with experience in questionnaire development who evaluated the survey for clarity, consistency and errors. Secondly, a pilot was conducted on 8 participants to determine the acceptability and clarity of the questions, and to confirm its face validity. The questionnaire was modified accordingly, and the responses obtained in the pilot study were excluded from the study analysis.

For centers to participate in the survey, they had to meet the following eligibility criteria: (1) tertiary care hospital, (2) more than 30 intensive care unit (ICU) beds, (3) functional laboratory with supplies and personnel able to perform culture and full bacterial identification and antimicrobial susceptibility testing, and (4) infectious

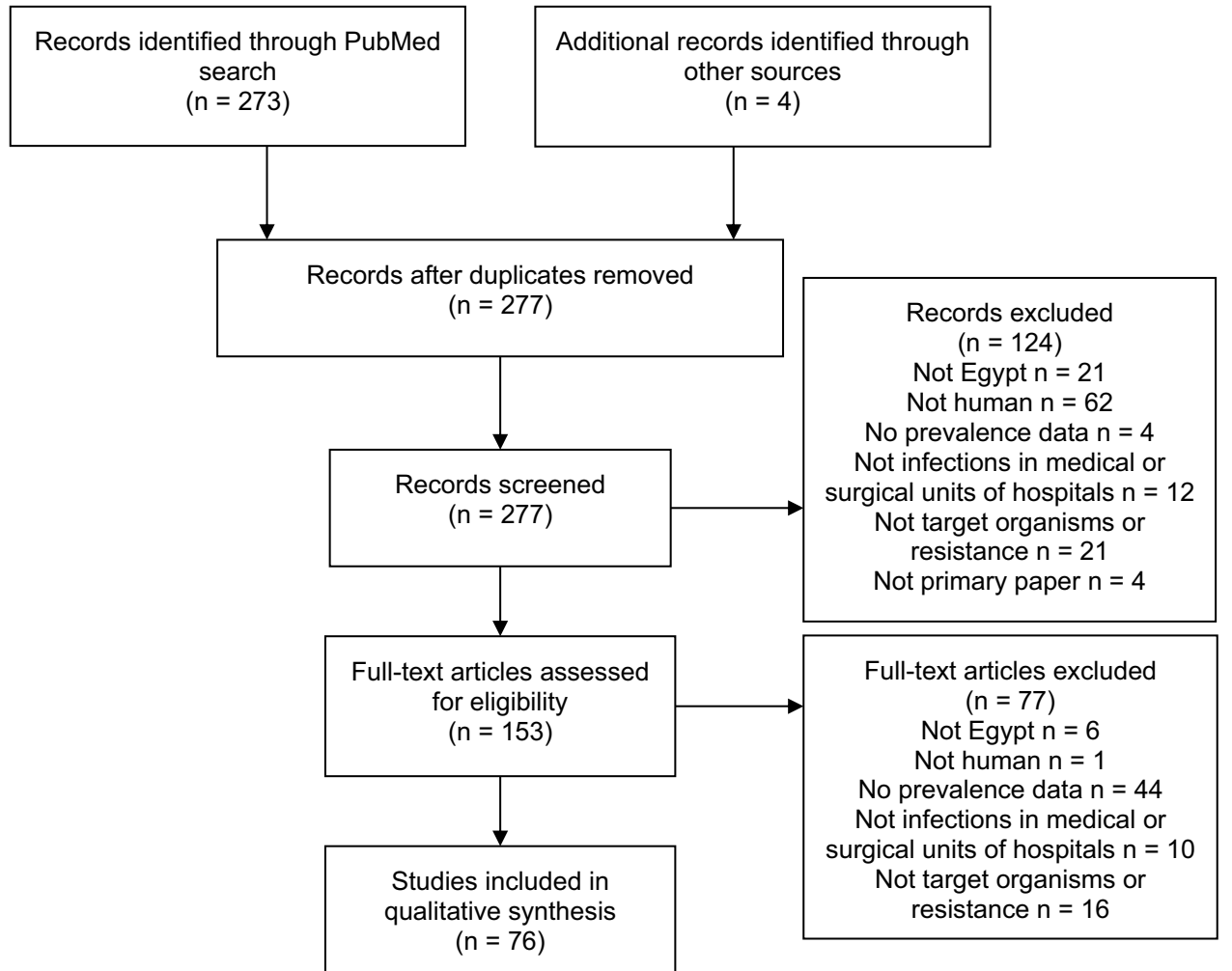

Figure I PRISMA flow diagram of literature search.

Notes: PRISMA figure adapted from Liberati A, Altman D, Tetzlaff J, et al. The PRISMA statement for reporting systematic reviews and meta-analyses of studies that evaluate health care interventions: explanation and elaboration. Journal of clinical epidemiology. 2009;62(I0). Creative Commons. 
A

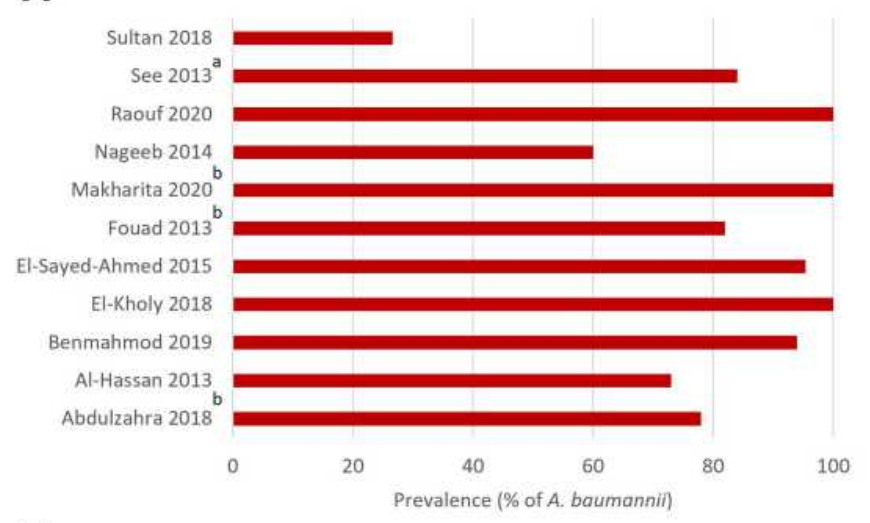

B

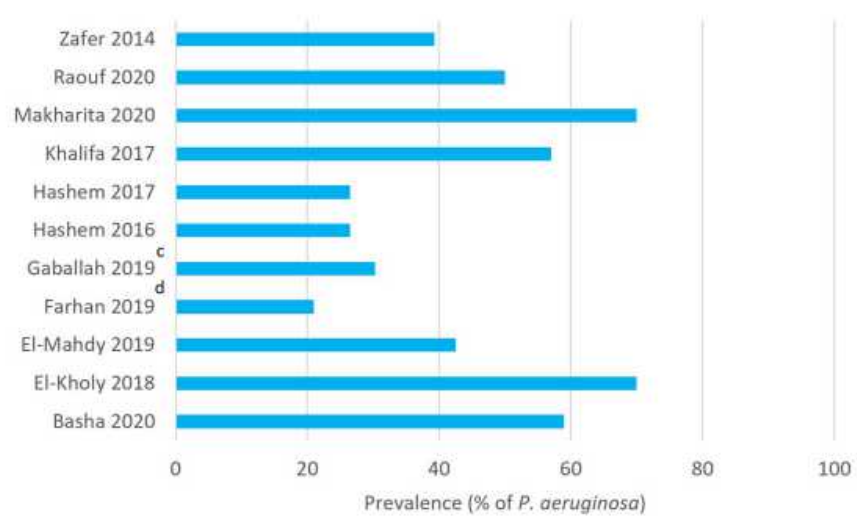

C

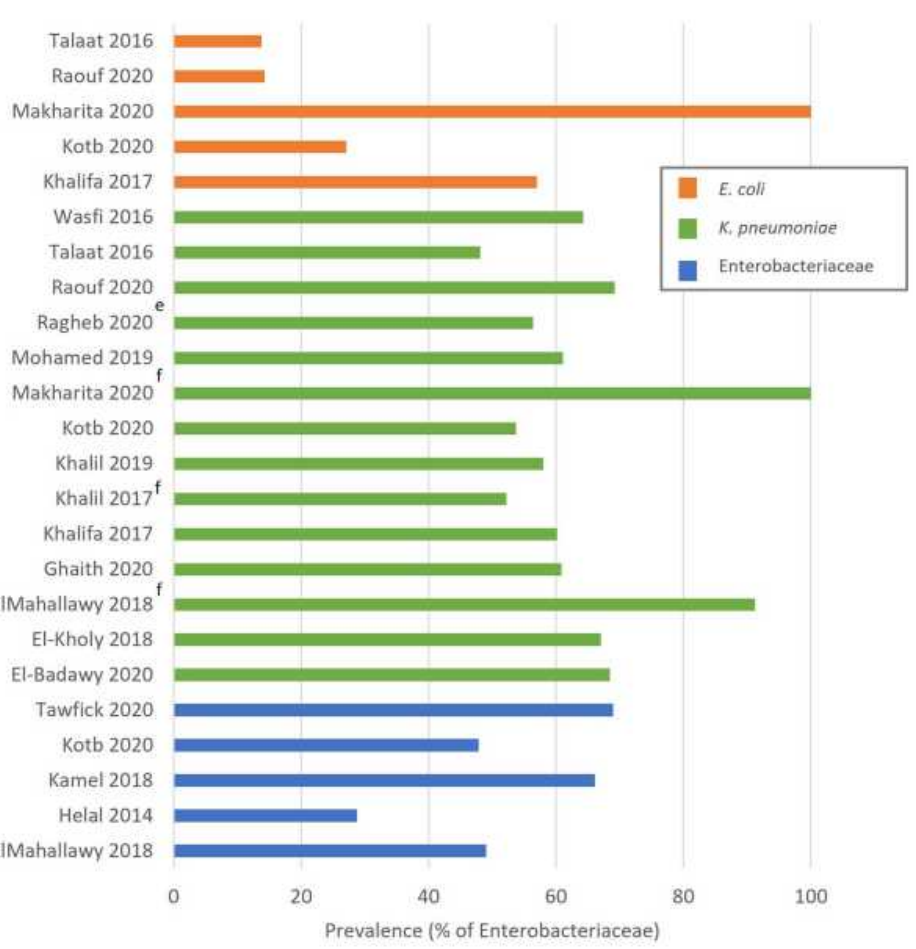

Figure 2 Summary of the prevalence (\%) of reported carbapenem-resistant/carbapenemase-producing Gram-negative species: (A) A. baumanii; (B) P. aeruginosa; and (C) Enterobacteriaceae.

Notes: Data from references ${ }^{27,32-63}$. ${ }^{a}$ Acinetobacter spp.; ${ }^{b} \%$ of CRAB; ${ }^{c} \%$ of $P$. aeruginosa isolates resistant to one or more $\beta$-lactams; ${ }^{\mathrm{d}} \%$ of MDR P. aeruginosa; ${ }^{\mathrm{e}} \%$ of carbapenem-non-susceptible $K$. pneumoniae; $\%$ of CRKP 
disease physicians or ICU physicians with expertise in infectious diseases and AMR, based on selection criteria for Egypt's national hospital-acquired infections (HAI) surveillance program. ${ }^{27}$ The survey was circulated to physicians on September 21, 2020 with a follow-up sent on September 28, 2020. The survey was closed on October 20, 2020. Analysis included descriptive statistics of survey responses, median and interquartile range (IQR). Responses were summarized where a response was given, excluding missing values. All statistical analyses were performed using StataIC (StataCorp, Version 16).
The study protocol was approved by the Research Ethics Committee of Cairo University Medical School in accordance with the Declaration of Helsinki (Ethical approval number: N-13-2020). All physicians who responded to the survey consented to participation in the study and publication of the data.

\section{Results}

\section{Literature Search}

A total of 277 studies were screened. It was deemed that 201 publications were not eligible for inclusion. A total of 76 publications were included (Figure 1).

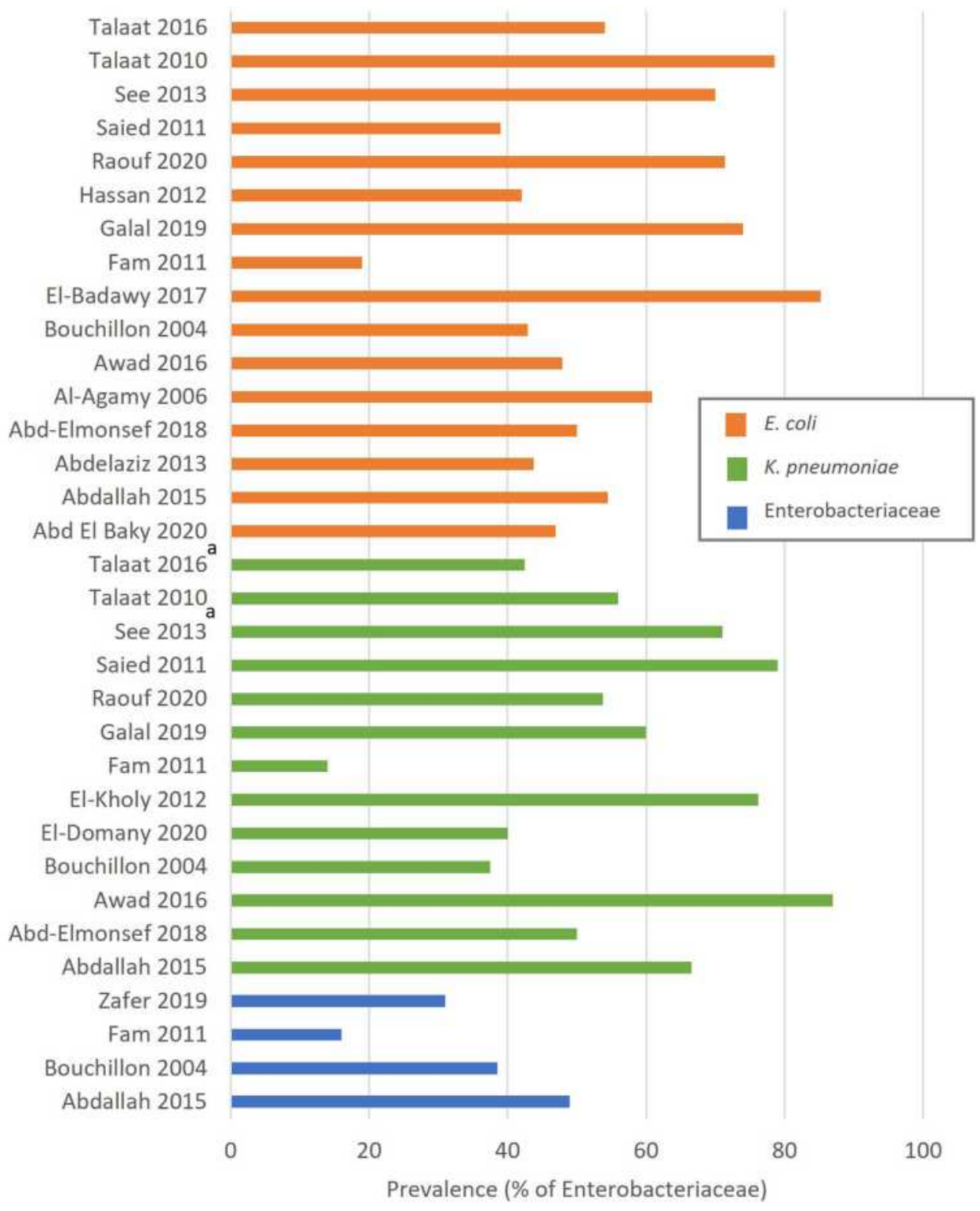

Figure 3 Summary of the prevalence (\%) of ESBL-producing/third-generation cephalosporin-resistant Enterobacteriaceae (ESBL-E). Notes: Data from references $27,33,42,64-79$. ${ }^{\text {a }}$ Klebsiella spp. 
Prevalence of MDR Gram-negative infections in Egypt described in the literature is summarized in Figures 2-8, details of the studies are provided in Supplementary File 1 and additional data in Supplementary File 2. Reports of multidrug resistance in Gram-negative bacterial species are high in Egypt with $21-100 \%$ of $P$. aeruginosa, $30-100 \%$ of A. baumannii, $42.5-98.73 \%$ of $K$. pneumoniae and $22.8-$ 96.07\% of Escherichia coli defined as MDR.

Carbapenem resistance was reported in $26.6-100 \%$ of A. baumannii, 21-70\% of P. aeruginosa and $28.8-69 \%$ of Enterobacteriaceae (K. pneumoniae $48.1-100 \%$ and E. coli 13.8-100\%) in Egypt (Figure 2). ESBL production or third-generation cephalosporin resistance was reported in $16-48.93 \%$ of Enterobacteriaceae, $14-87 \%$ of E. coli, and $19-85.24 \%$ of $K$. pneumoniae, respectively (Figure 3). Carbapenemase genes New Delhi metallo- $\beta$-lactamase (NDM) and K. pneumoniae carbapenemase (KPC) were commonly reported in A. baumannii with a prevalence of
$0-39.3 \%$ and $0-28.6 \%$, respectively (Figure 4). Verona integron-encoded metallo- $\beta$-lactamase (VIM) and imipenemase metallo- $\beta$-lactamase (IMP) were commonly reported in $P$. aeruginosa with a prevalence of $0-100 \%$ and $0-42.8 \%$, respectively (Figure 5 ). NDM and oxacillin carbapenemase 48 (OXA-48) genes were commonly reported in Enterobacteriaceae with a prevalence of 26.04-68.88\% and $30-58.62 \%$, respectively (Figure 6). NDM genes were also commonly reported in E.coli with a prevalence of $13.7-80.39 \%$ (Figure 7). In K. pneumoniae, there was a high prevalence of KPC, NDM and OXA-48 genes at $0-95.8 \%, 20.9-100 \%$, and 0-80.65\%, respectively (Figure 8). ESBL genes cefotaximase-Munich (CTX-M), sulphydryl variable (SHV) and Temoniera (TEM) were highly prevalent in $20.2-89.13 \%$, $10.1-50 \%$ and $31.5-56.52 \%$ of Enterobacteriaceae, respectively (Figure 6). In E. coli, CTX-M and TEM prevalence was $32.8-100 \%$ and $4.2-100 \%$, respectively

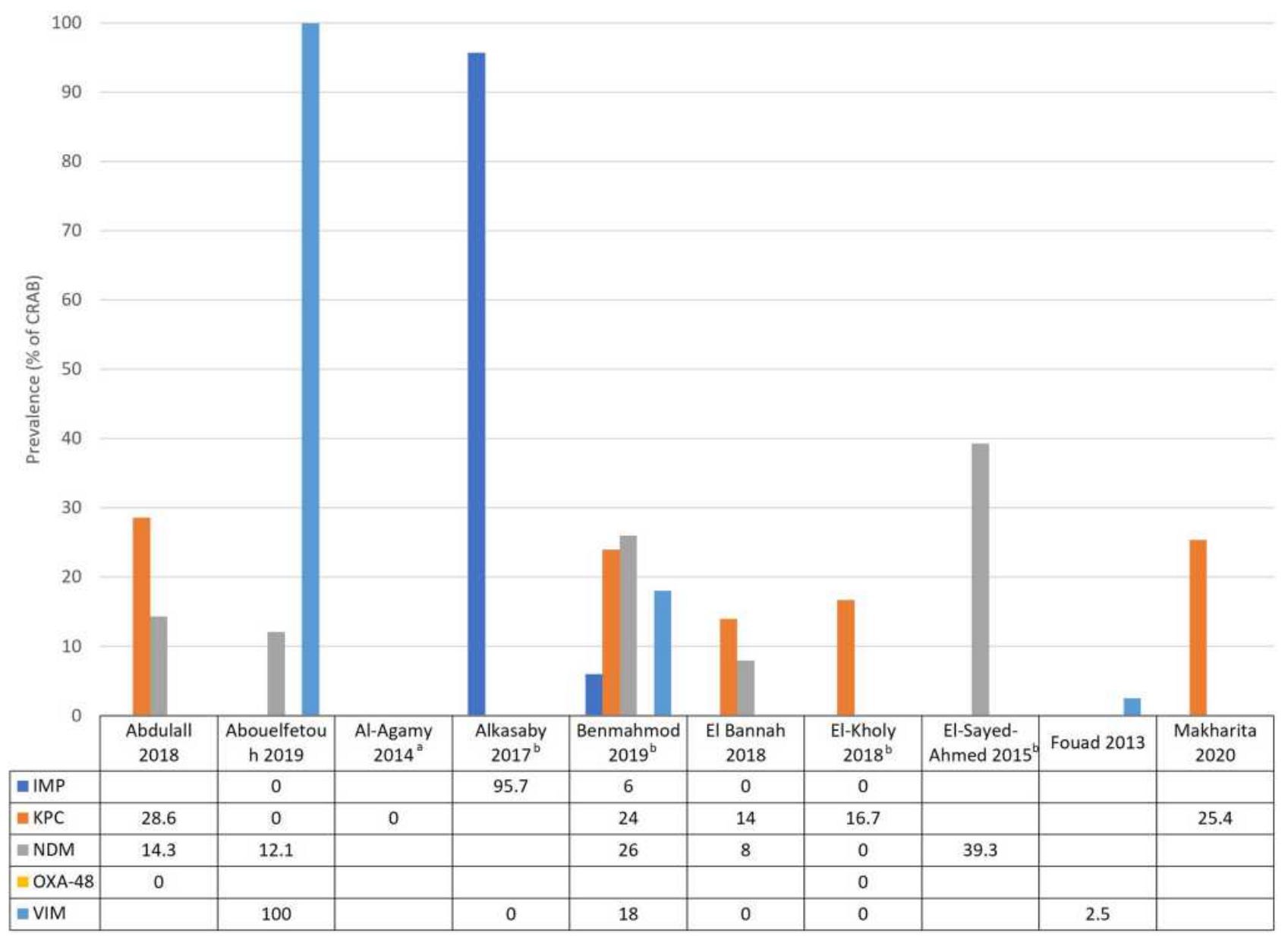

Figure 4 Summary of the prevalence (\%) of carbapenemase genes in A. baumannii. Notes:Data from references ${ }^{36-40,80-84}$ a\% of imipenem-insusceptible A. baumannii; ${ }^{\text {b } \% ~ o f ~}$ A. baumannii. 
120

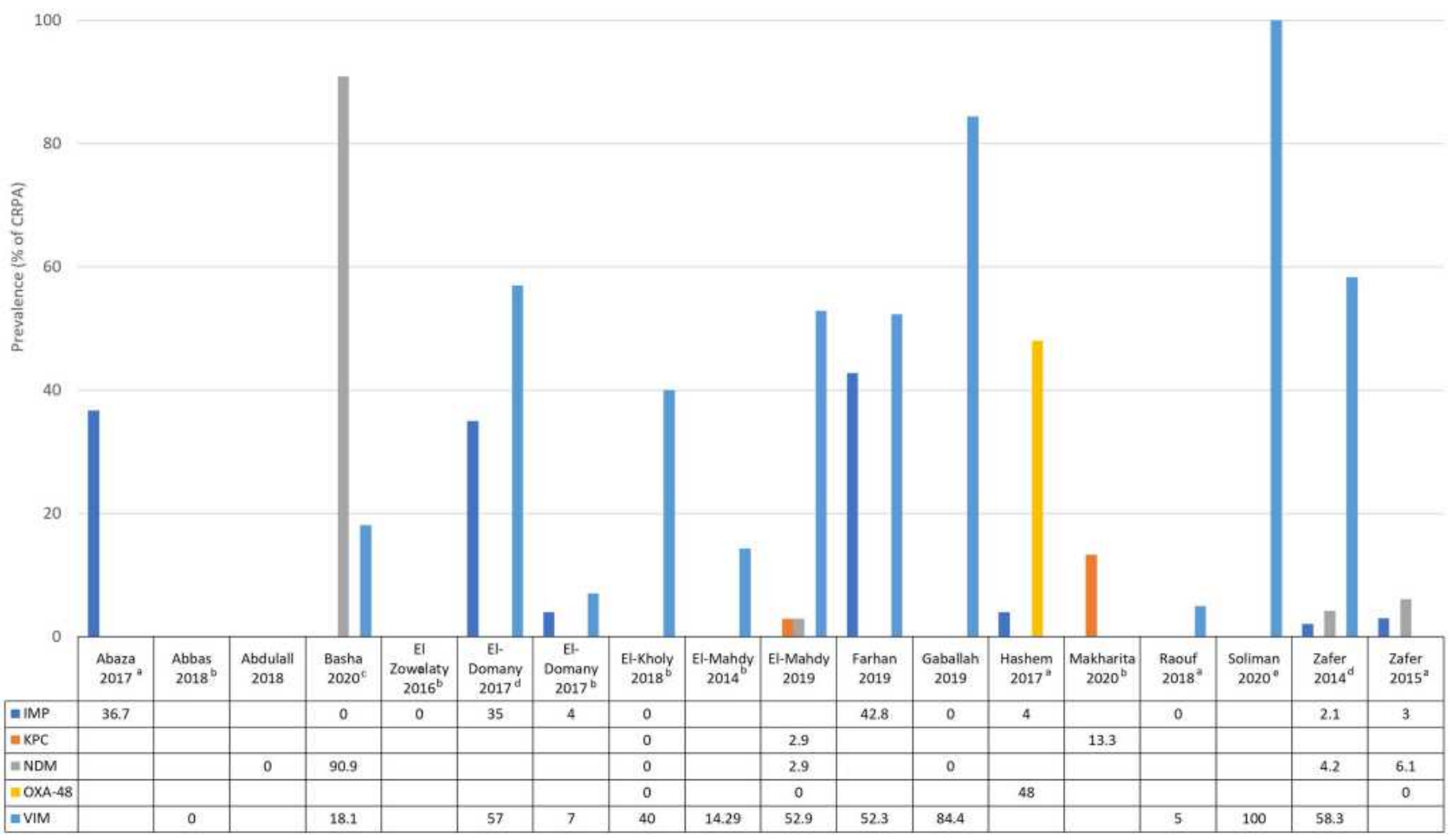

Figure 5 Summary of the prevalence (\%) of carbapenemase genes in P. aeruginosa.

Notes: Data from references ${ }^{37,40,44-47,49,51,80,85-92}$. $\%$ of MBL-producing $P$. aeruginosa; ${ }^{b} \%$ of $P$. aeruginosa isolates resistant to one or more $\beta$-lactams; ${ }^{c} \%$ of XDR-CRPA; ${ }^{\circ} \%$ of imipenem-resistant $P$. aeruginosa; ${ }^{e} \%$ of carbapenemase genes

(Figure 7). In K. pneumoniae, CTX-M, SHV and TEM prevalence was $38.9-100 \%, 0-81 \%$ and $0.4-57.1 \%$, respectively (Figure 8).

\section{Survey Results}

Survey results are discussed below and provided in full in Supplementary File 3.

\section{Participating Physicians}

Of the 99 physicians who were sent the survey, 46 (46.5\%) responded. Where specialty was specified $(\mathrm{n}=40)$, $53.49 \%(\mathrm{n}=23)$ of the physicians were intensivists, $39.53 \%(\mathrm{n}=17)$ microbiologists, $4.65 \%(\mathrm{n}=2)$ infectious disease specialists, and $2.33 \%(\mathrm{n}=1)$ internal medicine specialists. Responding physicians were from 14 centers across Egypt.

\section{Risk Factors and Types of HAl}

Respondents reported the most common risk factors for MDR Gram-negative infections were ventilated patients $(67.4 \%)$ or those experiencing prolonged hospitalization
(53.5\%). Chronic disease (34.9\%), prior antibiotic use (32.6\%) and elderly (23.3\%) were also relatively common (Figure 9). The most common type of HAI in their centers was HAP (65.9\%), followed by UTI (12.2\%), and BSI (9.8\%) (Figure 10, Figure 11, Figure 12, Figure 13).

\section{Prevalence of Gram-Negative MDR Species}

Median (IQR) prevalence of Gram-negative species, Gram-negative MDR species and carbapenemases reported by responding centers are shown in Figures 11-13. Most respondents reported increased prevalence of MDR gram-negative infections over the past 5 years in their centers $(95.83 \%)$, with most of these reporting an increase of $25-50 \%(60.87 \%)$. Many respondents predicted that prevalence of such infections is likely to increase over the next 10 years $(58.33 \%)$.

\section{Capabilities}

Whilst $16.67 \%$ of respondents reported best-practice capabilities, the majority of respondents reported either good $(37.50 \%)$ or moderate $(29.17 \%)$ AMR surveillance 


\section{0}

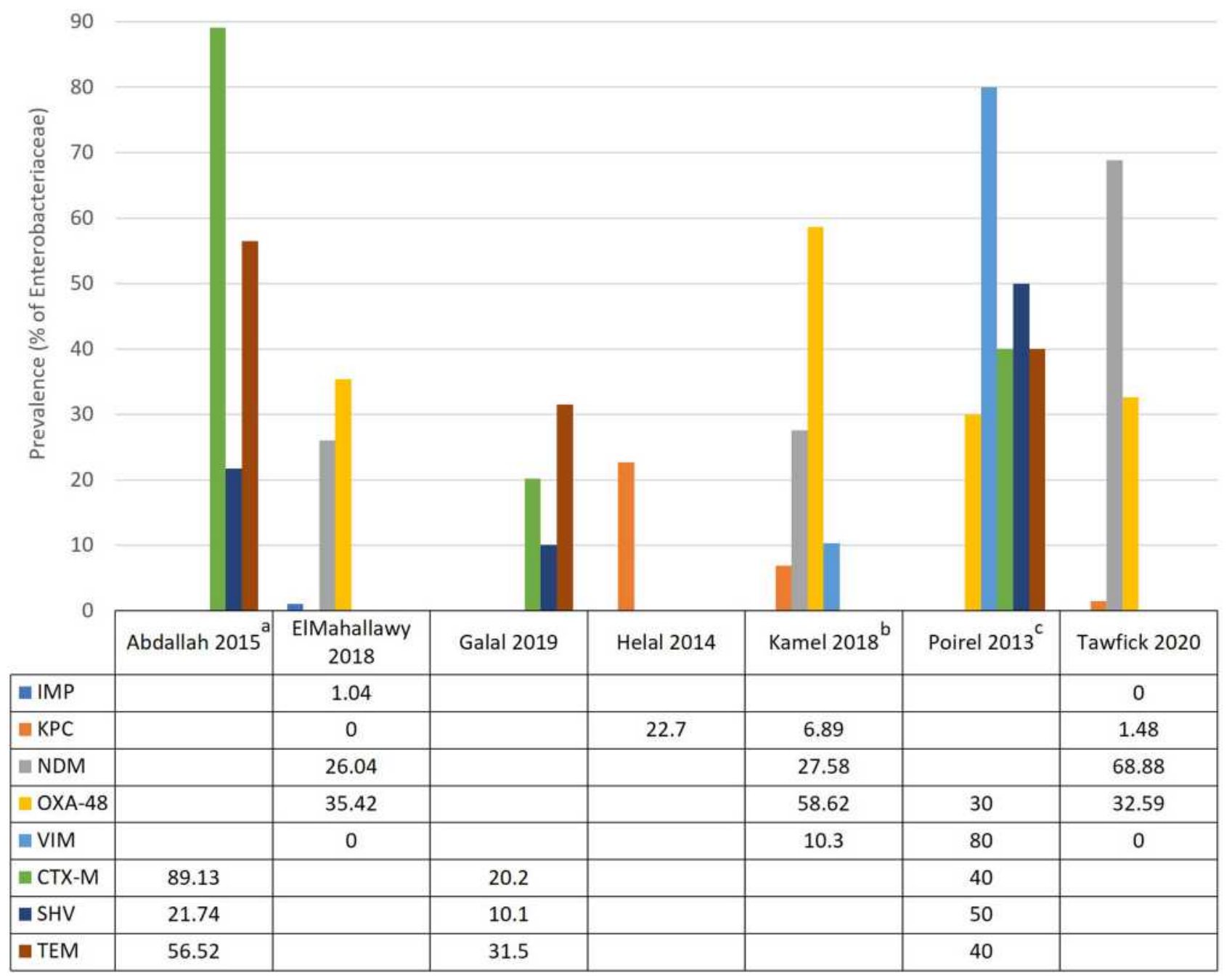

Figure 6 Summary of the prevalence (\%) of carbapenemase and ESBL genes in Enterobacteriaceae. Notes: Data from references ${ }^{52-55,64,72,93}$. ${ }^{a} \%$ of ESBL-E; ${ }^{b} \%$ of carbapenemase genes; ${ }^{c} \%$ of CRE

capabilities in their centers, with more than half (58.33\%) of respondents reporting that surveillance cultures were being performed for colonization at their center. In terms of antimicrobial susceptibility testing (AST), a large proportion of respondents reported that their centers performed culture antimicrobial susceptibility testing for all ICU patients (86.36\%). One respondent reported that only patients at high risk of MDR infection were tested. Vitek ${ }^{\circledR}$ 2 was the most common automated AST system available to the respondents $(50 \%)$. Other available automated AST systems or devices included Beckman Coulter Microscan ${ }^{\circledR}$ (5\%), BD Phoenix ${ }^{\mathrm{TM}}$ Emerge $^{\mathrm{TM}} \quad(5 \%)$, BioFire $^{\circledR}$ FilmArray $^{\circledR}$ (20\%), and other $(15 \%)$. Most respondents reported that their centers were changing AST technology to take advantage of susceptibility panels with a greater range of more recent antimicrobial agents $(81.82 \%)$. Only seven $(35 \%)$ respondents reported having access to rapid AMR detection diagnostics, with singleplex PCR $(n=3)$, multiplex PCR $(n=2)$, microarray nanoparticle identification $(n=2)$, and GeneXpert ${ }^{\circledR}(n=1)$ being the available platforms specified.

\section{Clinical Practice Procedures}

The Infectious Diseases Society of America (IDSA) was the most used source of guideline recommendations in clinical practice $(65 \%)$, with national guidelines $(40 \%)$, hospital guidelines (30\%), European Society of Clinical Microbiology and Infectious Diseases (ESCMID) (25\%), WHO (20\%), and The British Society for Antimicrobial Chemotherapy (5\%) also reported. Half of physicians also 


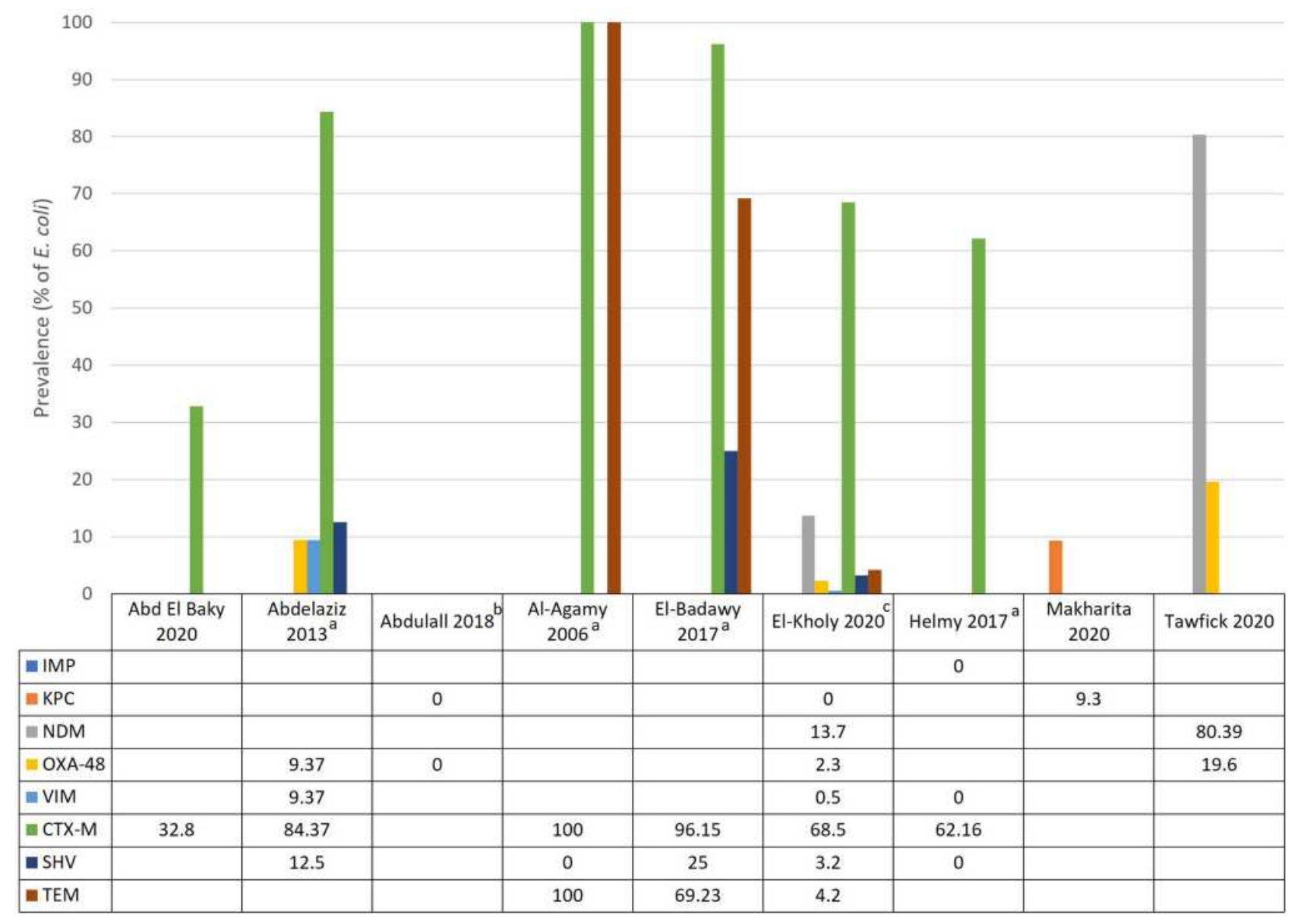

Figure 7 Summary of the prevalence (\%) of carbapenemase and ESBL genes in E. coli.

Notes: Data from references ${ }^{40,55,75-78,80,94,95}$. a\% of ESBL-producing/third-generation cephalosporin-resistant E. coli; ${ }^{\circ} \%$ of CREC; ${ }^{\circ} \%$ MDR E. coli

reported other guidelines that significantly impacted on their clinical practice in treating Gram-negative infections. Most respondents reported that the guidelines implemented were either partially adequate $(45 \%)$ or not adequate (40\%) for managing MDR gram-negative infections. Whilst $60 \%$ of respondents reported hospital-specific protocols or standard operating procedures for the treatment of Gram-negative infections, the majority (75\%) reported that Gram-negative infection risk prediction protocols were not used. Twelve respondents $(65 \%)$ reported that local epidemiology data was used in treatment decisionmaking and contributed to antimicrobial stewardship (AMS), five respondents (25\%) reported that it was not used. Eleven respondents (55\%) reported the presence of a specific AMS program in their center.

\section{Barriers and Challenges}

More than half of respondents reported a lack of collaboration and communication between the laboratory and clinical staff (54.55\%) as one of the key issues relating to AMR surveillance; incomplete data (36.36\%) and lack of regulation governing surveillance $(31.82 \%)$ were also key issues. Cost of tests $(62.50 \%)$, knowledge gaps in clinicians of relevance to antimicrobial surveillance $(56.25 \%)$, speed of test result reporting (43.75\%), and availability of tests in laboratory $(37.50 \%)$ were barriers to ideal susceptibility testing. The cost of newer treatments (55\%), lack of access to newer antibiotics (50\%), lack of formal AMS programs (45\%), and clinical teams' poor compliance with recommendations (30\%) were considered barriers to successful management of MDR Gram-negative infections.

\section{Discussion}

The survey and the literature review both highlight the magnitude of the AMR problem across Egypt, with reports of very high rates of ESBL-E, CRE, CRAB, and CRPA. According to the survey, carbapenem resistance was 


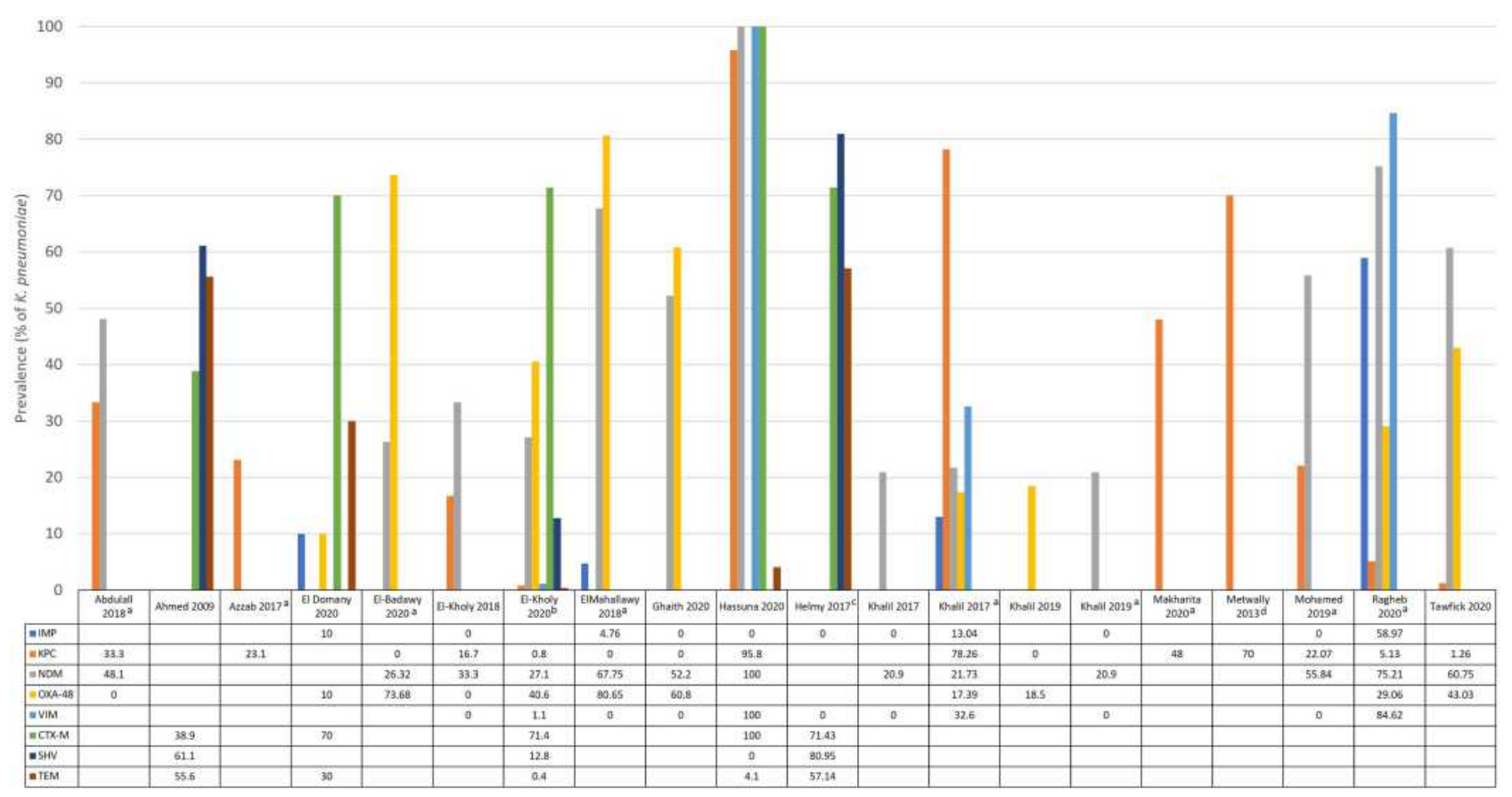

Figure 8 Summary of the prevalence (\%) of carbapenemase and ESBL genes in K. pneumoniae.

Notes: Data from references ${ }^{40,55-62,70,80,94-99}$ a $\%$ of carbapenemase-resistant/-producing K. pneumoniae; bo of MDR K. pneumoniae; ${ }^{\mathrm{c}} \%$ of ESBL-producing/third-generation cephalosporin-resistant K. pneumoniae; ${ }^{\text {d } \% ~ o f ~ e r t a p e n e m ~ n o n-s u s c e p t i b l e ~ K . ~ p n e u m o n i a e . ~}$

reported in $20 \%(10-45 \%)$ of E. coli, 35\% (25-60\%) of K. pneumoniae, $15 \%$ (3-40\%) of P. aeruginosa, and $10 \%$ (5-30\%) of $A$. baumannii. ESBL production was reported in $20 \% \quad(10-60 \%)$ of $E$. coli, $10 \% \quad(5-50 \%)$ of K. pneumoniae, and $17 \% \quad(7-20 \%)$ of other Enterobacteriaceae. Key challenges faced by physicians within the country relate to a lack of access to the

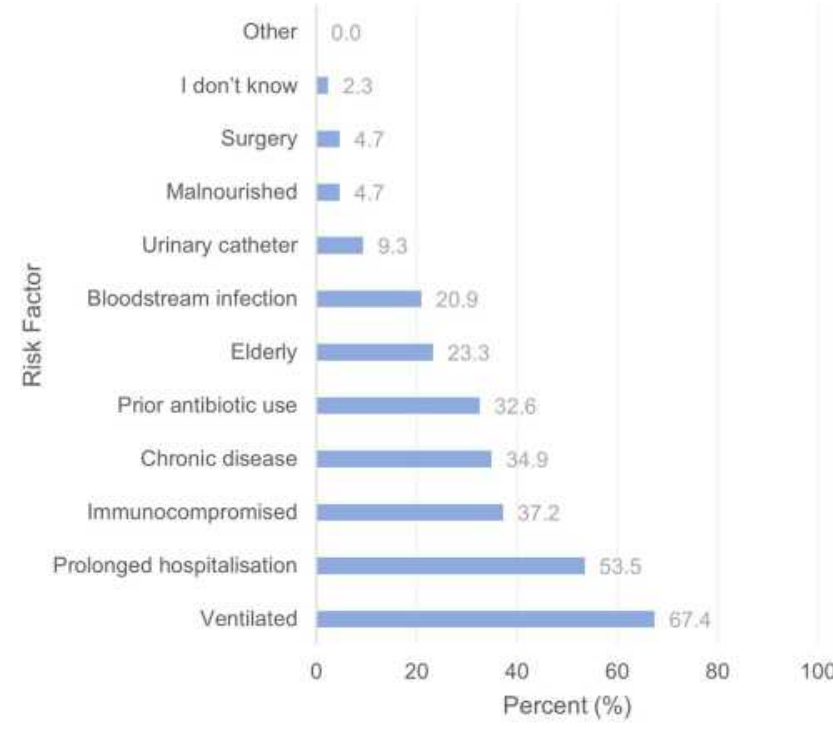

Figure 9 Risk factors for MDR Gram-negative infections. necessary tools, such as rapid diagnostics, molecular testing, local epidemiology data and newer antibiotics, as well as a lack of healthcare infrastructure, stewardship, regulation, and collaboration.

A recent review of the epidemiology of MDR infections across the Arab League has shown that Egypt reports high resistance levels compared to its neighbors. ${ }^{28}$ ESBLE prevalence was 4-25\% in the Gulf Cooperation Council (GCC), 31-66\% in the Levant, and 9-35\% in the rest of the African countries versus $55 \%$ in Egypt. ${ }^{28} \mathrm{CRE}$

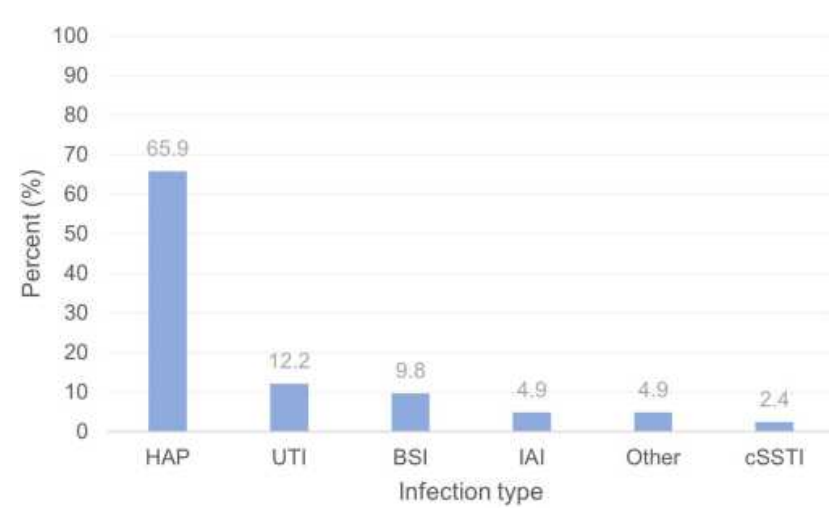

Figure 10 Types of $\mathrm{HAl}$ in Egyptian centers.

Abbreviations: CSSTI, complicated skin and soft-tissue infection; BSI, bloodstream infection; HAP, hospital-acquired pneumonia; IAI, intra-abdominal infection; UTI, urinary tract infection. 

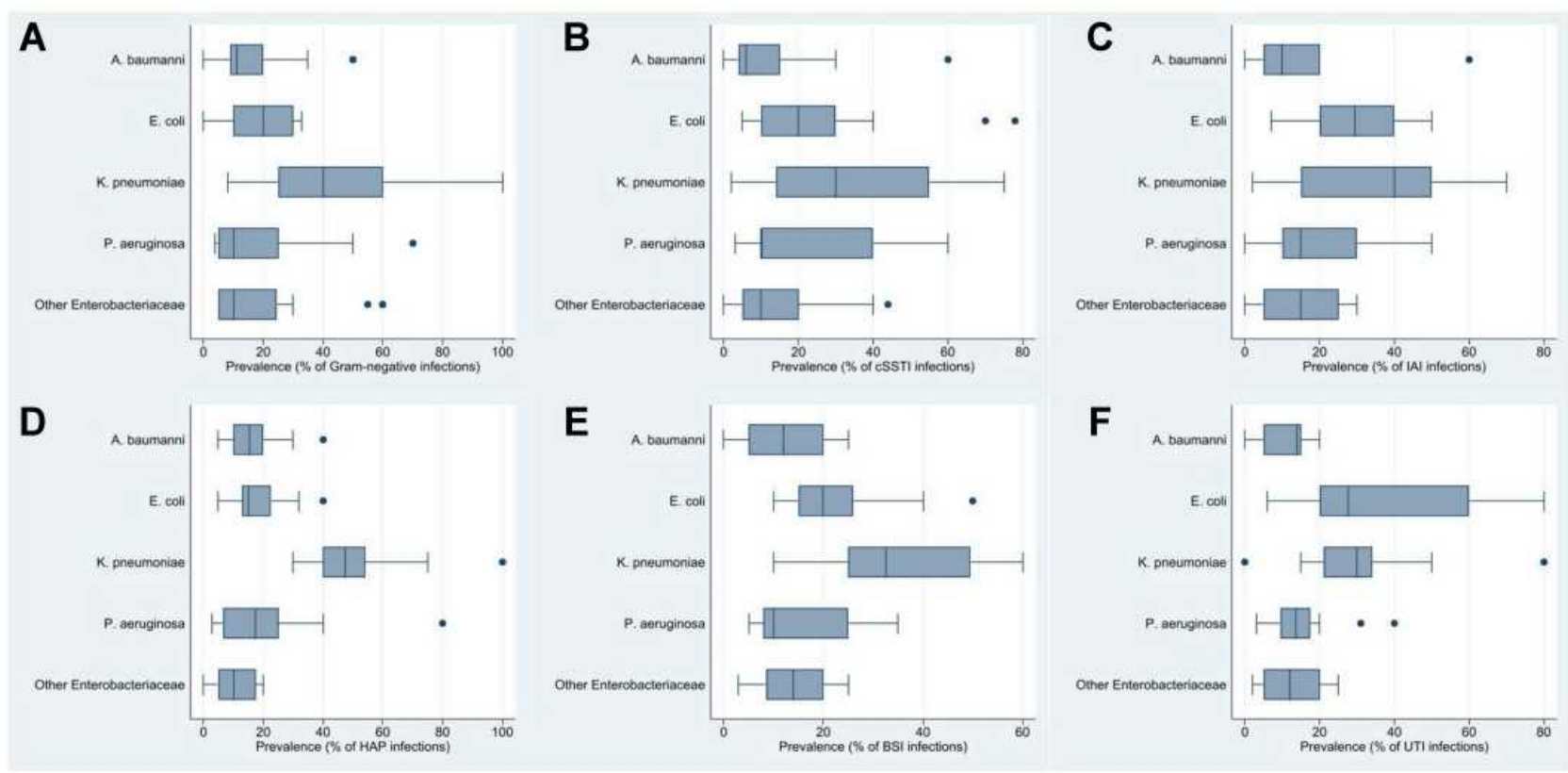

Figure I I Gram-negative species prevalence across Egyptian centers: (A) all Gram-negative infections; (B) cSSTI; (c) IAl; (D) HAP; (E) BSI; (F) UTI. Abbreviations: cSSTI, complicated skin and soft-tissue infection; BSI, bloodstream infection; HAP, hospital-acquired pneumonia; IAI, intra-abdominal infection; UTI, urinary tract infection.

prevalence was $0-1 \%$ in the GCC, $1-22.5 \%$ in the Levant, and $<2 \%$ in the rest of the African countries versus $28 \%$ in Egypt. CRPA prevalence was $3-21 \%$ in the GCC, $28-93 \%$ in the Levant, and $19-56 \%$ in the rest of the African countries versus $51 \%$ in Egypt. Finally, CRAB prevalence was $36-100 \%$ in the GCC, $64-89 \%$ in the Levant, and $75-$ $88 \%$ in the rest of the African countries versus $93 \%$ in Egypt. ${ }^{28}$ Such high levels of resistance in Egypt compared

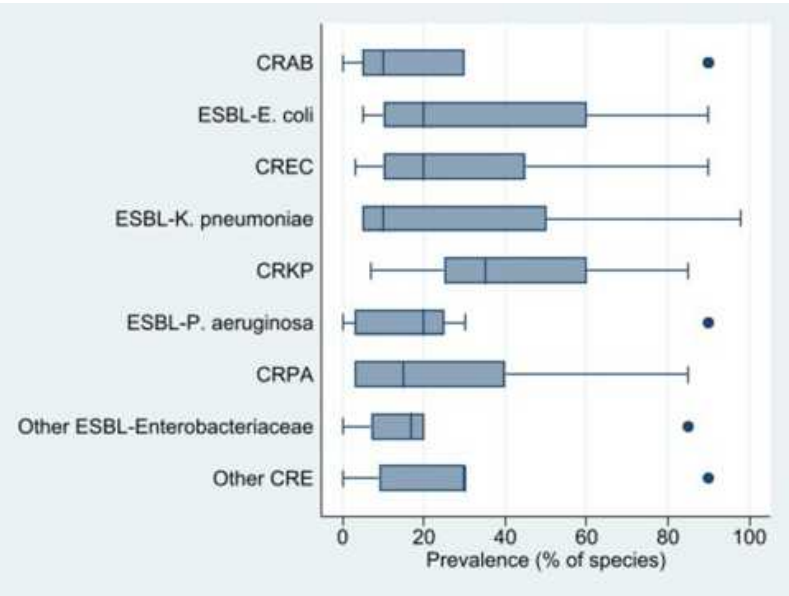

Figure 12 Prevalence of MDR Gram-negative species.

Abbreviations: CRAB, carbapenem-resistant A. baumannii; CRE, carbapenemresistant Enterobacteriaceae; CREC, carbapenem-resistant E. coli; CRKP, carbapenem-resistant $K$. pneumoniae; ESBL, extended-spectrum $\beta$-lactamase. to neighboring countries are thought to be the result of challenges in infection prevention and control, ${ }^{29}$ high levels of antibiotic consumption, ${ }^{30}$ and use in non-human populations. $^{31}$ The levels of resistance reported in our online survey are lower than those reported within this review, potentially a result of differences in the populations or hospitals included in both studies.

The survey and the literature review also highlight the large variation in prevalence of MDR infections across hospitals or centers. Some of this variability might be a result of many studies reporting prevalence within a small number of centers or hospitals (typically between one and six hospitals) or with small number of samples or isolates. However, three published studies have described prevalence of MDR Gram-negative HAI via Egypt's national HAI surveillance program, reporting data from up to 310 ICUs from 72 hospitals. ${ }^{27,32,33}$ Whilst historically Egypt has reported limitations in its surveillance and microbiology capabilities, ${ }^{29}$ the national HAI surveillance program paves the way to obtaining epidemiological data which will help to inform infection control and prevention strategies. ${ }^{27} \mathrm{~A}$ further potential reason for the variability in prevalence may be the nature of the Egyptian healthcare system: a complex and fragmented network of Ministry of Health and Population facilities, private hospitals, university hospitals, and military hospitals, as well as other ministry-associated hospitals with varied levels and availability of medical 

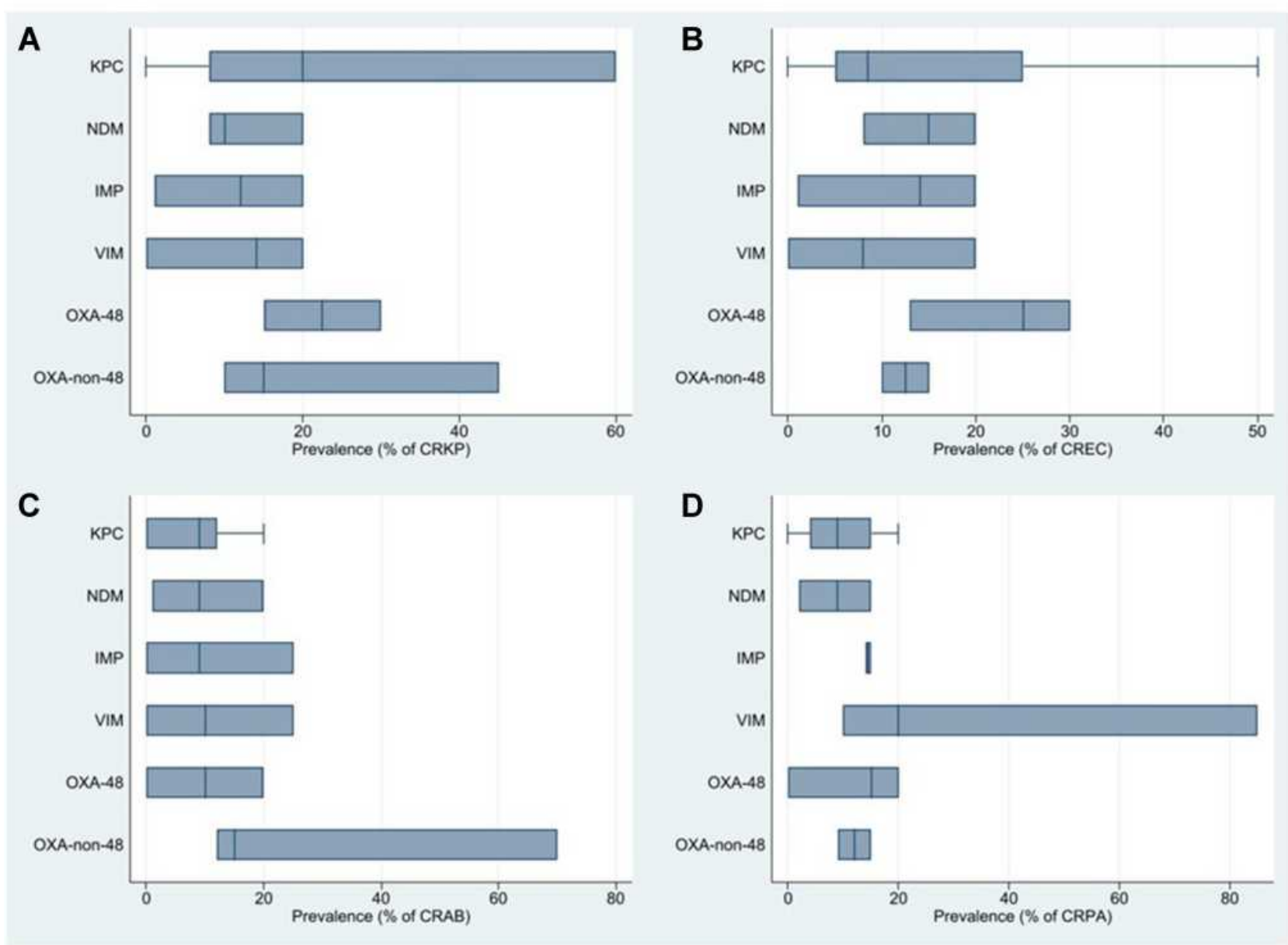

Figure 13 Prevalence of carbapenemases: (A) CRKP; (B) CREC; (C) CRAB; (D) CRPA.

Abbreviations: CRAB, carbapenem-resistant A. baumannii; CRE, carbapenem-resistant Enterobacteriaceae; CREC, carbapenem-resistant E. coli; CRKP, carbapenemresistant K. pneumoniae; IMP, imipenemase metallo- $\beta$-lactamase; KPC, Klebsiella pneumoniae carbapenemase; NDM, New Delhi metallo- $\beta$-lactamase; OXA-48, oxacillin carbapenemase 48; OXA-non-48, oxacillin carbapenemase (non-48); VIM, Verona integron-encoded metallo- $\beta$-lactamase.

services. ${ }^{29}$ This poses significant challenges in terms of AMS and AMR control initiatives. Furthermore, in contrast to many countries, the infectious disease specialty is almost absent in Egypt, which impedes prudent use of antimicrobials, adequate cross-specialty communication, institution-wide infectious disease leadership, and the development and management of AMS systems. Finally, the process of data collection varies between different centers, with no single authority responsible for organizing data collection concerning AMR. A further gap in MDR Gram-negative infection reporting in Egypt includes the lack of data concerning community acquired MDR infections.

The survey has provided valuable information concerning MDR Gram-negative infections in Egypt and has collected a broad range of data concerning prevalence of such infections, capabilities of centers, and key barriers and issues faced in AMR surveillance, susceptibility testing, and management of MDR Gram-negative infections. The survey was anonymous to encourage honest reporting of data by physicians; nevertheless, the accuracy of the data reported cannot be verified. Furthermore, only tertiary care hospitals with capabilities to perform bacterial identification and AST were included in the survey; this has the potential to overestimate the prevalence of MDR Gram-negative species across the country. The number of responses to questions relating to carbapenemase prevalence within the survey was low, resulting from the lack of molecular testing capabilities within the country. Therefore, cautious interpretation of carbapenemase prevalence is required. Future efforts in Egypt should focus on collecting additional data concerning molecular characterization of resistance genes across a variety of healthcare centers in Egypt. Such molecular data will provide a true understanding of the resistance patterns in MDR Gram-negative infections in the country, facilitate future 
use of novel antimicrobials such as BL-BLIs and, therefore, is required to combat recent trends of increasing antimicrobial resistance. Future steps in the fight against AMR in Egypt should include antimicrobial stewardship to optimize the use of antibiotics, improve laboratory capacities and national initiatives to control antimicrobial resistance.

\section{Conclusion}

The survey has provided valuable information concerning the epidemiology and resistance patterns of MDR Gramnegative infections in Egypt, whilst highlighting the challenges and barriers faced by physicians. Collective efforts to overcome these challenges and reduce the burden of MDR Gram-negative infections across the country are urgent and critical to preventing the spread of multidrug resistance. Nationwide initiatives are needed for understanding the AMR trends in the country, capacity building of laboratories and staff to correctly and timely identify AMR as well as introducing newer antimicrobials for treatment of MDR Gram-negative infections.

\section{Acknowledgments}

We thank all participating physicians who completed the survey. Medical writing support was provided by Dr. Abigail Holland of Connect Communications, Dubai.

\section{Funding}

This work, including medical writing support, was supported by Pfizer, Egypt.

\section{Disclosure}

Professor Noha Elsharnouby reports non-financial support from Pfizer, during the conduct of the study. Dr Mohamed Abdel Aziz, Ahmed Mohamed Helmy, and Ramy Kotb report being employees of Pfizer during the conduct of the study and outside the submitted work. The authors report no other potential conflicts of interest for this work.

\section{References}

1. Eichenberger EM, Thaden JT. Epidemiology and mechanisms of resistance of extensively drug resistant Gram-negative bacteria. Antibiotics (Basel). 2019;8(2). doi:10.3390/antibiotics8020037

2. Poole K. Multidrug resistance in Gram-negative bacteria. Curr Opin Microbiol. 2001;4(5):500-508. doi:10.1016/S1369-5274(00)00242-3

3. Gaynes R, Edwards JR; National Nosocomial Infections Surveillance $\mathrm{S}$. Overview of nosocomial infections caused by gram-negative bacilli. Clin Infect Dis. 2005;41(6):848-854. doi:10.1086/432803

4. Sartelli M, Catena F, Ansaloni L, et al. Complicated intra-abdominal infections worldwide: the definitive data of the CIAOW Study. World J Emerg Surg. 2014;9(1):37. doi:10.1186/1749-7922-9-37
5. Magiorakos AP, Srinivasan A, Carey RB, et al. Multidrug-resistant, extensively drug-resistant and pandrug-resistant bacteria: an international expert proposal for interim standard definitions for acquired resistance. Clin Microbiol Infect. 2012;18(3):268-281. doi:10.1111/ j.1469-0691.2011.03570.x

6. Kaye KS, Pogue JM. Infections caused by resistant Gram-negative bacteria: epidemiology and management. Pharmacotherapy. 2015;35 (10):949-962. doi:10.1002/phar.1636

7. World Health Organization. Global priority list of antibiotic-resistant bacteria to guide research, discovery, and development of new antibiotics; 2017. Available from: https://www.who.int/medicines/pub lications/global-priority-list-antibiotic-resistant-bacteria/en/.

Accessed November 26, 2020.

8. Codjoe FS, Donkor ES. Carbapenem resistance: a review. Med Sci (Basel). 2017;6(1). doi:10.3390/medsci6010001

9. Corcione S, Lupia T, Maraolo AE, Mornese Pinna S, Gentile I, De Rosa FG. Carbapenem-sparing strategy: carbapenemase, treatment, and stewardship. Curr Opin Infect Dis. 2019;32(6):663-673. doi:10.1097/QCO.0000000000000598

10. Bassetti M, Peghin M, Vena A, Giacobbe DR. Treatment of infections due to MDR Gram-negative bacteria. Front Med (Lausanne). 2019;6:74. doi:10.3389/fmed.2019.00074

11. Li J, Nation RL, Turnidge JD, et al. Colistin: the re-emerging antibiotic for multidrug-resistant Gram-negative bacterial infections. Lancet Infect Dis. 2006;6(9):589-601. doi:10.1016/S1473-3099(06) 70580-1

12. Panidis D, Markantonis SL, Boutzouka E, Karatzas S, Baltopoulos G. Penetration of gentamicin into the alveolar lining fluid of critically ill patients with ventilator-associated pneumonia. Chest. 2005;128 (2):545-552. doi:10.1378/chest.128.2.545

13. Zusman O, Avni T, Leibovici L, et al. Systematic review and meta-analysis of in vitro synergy of polymyxins and carbapenems. Antimicrob Agents Chemother. 2013;57(10):5104-5111. doi:10.1128/ AAC.01230-13

14. Grabein B, Graninger W, Rodriguez Bano J, Dinh A, Liesenfeld DB. Intravenous fosfomycin-back to the future. Systematic review and meta-analysis of the clinical literature. Clin Microbiol Infect. 2017;23 (6):363-372. doi:10.1016/j.cmi.2016.12.005

15. Sirijatuphat R, Thamlikitkul V. Preliminary study of colistin versus colistin plus fosfomycin for treatment of carbapenem-resistant Acinetobacter baumannii infections. Antimicrob Agents Chemother. 2014;58(9):5598-5601. doi:10.1128/AAC.02435-13

16. Montravers P, Bassetti M. The ideal patient profile for new beta-lactam/beta-lactamase inhibitors. Curr Opin Infect Dis. 2018;31(6):587-593. doi:10.1097/QCO.0000000000000490

17. Lucasti C, Vasile L, Sandesc D, et al. Phase 2, Dose-Ranging Study of relebactam with imipenem-cilastatin in subjects with complicated intra-abdominal infection. Antimicrob Agents Chemother. 2016;60 (10):6234-6243. doi:10.1128/AAC.00633-16

18. Livermore DM, Warner M, Mushtaq S. Activity of MK-7655 combined with imipenem against Enterobacteriaceae and Pseudomonas aeruginosa. $J$ Antimicrob Chemother. 2013;68(10):2286-2290. doi: $10.1093 / \mathrm{jac} / \mathrm{dkt} 178$

19. Wright H, Bonomo RA, Paterson DL. New agents for the treatment of infections with Gram-negative bacteria: restoring the miracle or false dawn? Clin Microbiol Infect. 2017;23(10):704-712. doi:10.1016/j.cmi.2017.09.001

20. Shields RK, Chen L, Cheng $\mathrm{S}$, et al. Emergence of ceftazidime-avibactam resistance due to plasmid-borne blaKPC-3 mutations during treatment of carbapenem-resistant klebsiella pneumoniae infections. Antimicrob Agents Chemother. 2017;61(3).

21. Sun D, Rubio-Aparicio D, Nelson K, Dudley MN, Lomovskaya O. Meropenem-vaborbactam resistance selection, resistance prevention, and molecular mechanisms in mutants of KPC-producing klebsiella pneumoniae. Antimicrob Agents Chemother. 2017;61(12). doi:10.1128/AAC.01694-17 
22. MacVane SH, Pandey R, Steed LL, Kreiswirth BN, Chen L. Emergence of ceftolozane-tazobactam-resistant pseudomonas aeruginosa during treatment is mediated by a single AmpC structural mutation. Antimicrob Agents Chemother. 2017;61(12). doi:10.1128/ AAC.01183-17

23. Malik S, Kaminski M, Landman D, Quale J. Cefiderocol resistance in acinetobacter baumannii: roles of beta-lactamases, siderophore receptors, and penicillin binding protein 3. Antimicrob Agents Chemother. 2020;64(11). doi:10.1128/AAC.01221-20

24. Isler B, Doi Y, Bonomo RA, Paterson DL. New treatment options against carbapenem-resistant acinetobacter baumannii infections. Antimicrob Agents Chemother. 2019;63(1). doi:10.1128/ AAC.01110-18

25. Bolarinwa OA. Principles and methods of validity and reliability testing of questionnaires used in social and health science researches. Niger Postgrad Med J. 2015;22(4):195-201. doi:10.4103/1117-1936.173959

26. Chiwaridzo M, Chikasha TN, Naidoo N, et al. Content validity and test-retest reliability of a low back pain questionnaire in Zimbabwean adolescents. Arch Physiother. 2017;7:3. doi:10.1186/s40945-017-0031-y

27. Talaat M, El-Shokry M, El-Kholy J, et al. National surveillance of health care-associated infections in Egypt: developing a sustainable program in a resource-limited country. Am J Infect Control. 2016;44 (11):1296-1301. doi:10.1016/j.ajic.2016.04.212

28. Moghnieh RA, Kanafani ZA, Tabaja HZ, Sharara SL, Awad LS, Kanj SS. Epidemiology of common resistant bacterial pathogens in the countries of the Arab League. Lancet Infect Dis. 2018;18(12): e379-e394. doi:10.1016/S1473-3099(18)30414-6

29. Talaat M, Kandeel A, Rasslan O, et al. Evolution of infection control in Egypt: achievements and challenges. Am J Infect Control. 2006;34 (4):193-200. doi:10.1016/j.ajic.2005.05.028

30. Talaat M, Saied T, Kandeel A, et al. A point prevalence survey of antibiotic use in 18 hospitals in Egypt. Antibiotics (Basel). 2014;3 (3):450-460. doi:10.3390/antibiotics3030450

31. Dahshan H, Abd-Elall AM, Megahed AM, Abd-El-Kader MA, Nabawy EE. Veterinary antibiotic resistance, residues, and ecological risks in environmental samples obtained from poultry farms, Egypt. Environ Monit Assess. 2015;187(2):2. doi:10.1007/s10661-014-4218-3

32. Kotb S, Lyman M, Ismail G, et al. Epidemiology of Carbapenemresistant Enterobacteriaceae in Egyptian intensive care units using National Healthcare-associated infections surveillance data, 2011-2017. Antimicrob Resist Infect Control. 2020;9:2. doi:10.1186/s13756-019-0639-7

33. See I, Lessa FC, ElAta OA, et al. Incidence and pathogen distribution of healthcare-associated infections in pilot hospitals in Egypt. Infect Control Hosp Epidemiol. 2013;34(12):1281-1288. doi:10.1086/673985

34. Abdulzahra AT, Khalil MAF, Elkhatib WF. First report of colistin resistance among carbapenem-resistant Acinetobacter baumannii isolates recovered from hospitalized patients in Egypt. New Microbes New Infect. 2018;26:53-58. doi:10.1016/j.nmni.2018.08.007

35. Al-Hassan L, El Mehallawy H, Amyes SG. Diversity in Acinetobacter baumannii isolates from paediatric cancer patients in Egypt. Clin Microbiol Infect. 2013;19(11):1082-1088. doi:10.1111/1469-0691.12143

36. Benmahmod AB, Said HS, Ibrahim RH. Prevalence and mechanisms of carbapenem resistance among acinetobacter baumannii clinical isolates in Egypt. Microb Drug Resist. 2019;25(4):480-488. doi: $10.1089 / \mathrm{mdr} .2018 .0141$

37. El-Kholy AA, Elanany MG, Sherif MM, Gad MA. High prevalence of VIM, KPC, and NDM expression among surgical site infection pathogens in patients having emergency surgery. Surg Infect (Larchmt). 2018;19(6):629-633. doi:10.1089/sur.2018.088

38. El-Sayed-Ahmed MA, Amin MA, Tawakol WM, Loucif L, Bakour S, Rolain JM. High prevalence of bla(NDM-1) carbapenemase-encoding gene and 16S rRNA armA methyltransferase gene among Acinetobacter baumannii clinical Isolates in Egypt. Antimicrob Agents Chemother. 2015;59(6):3602-3605. doi:10.1128/AAC.04412-14
39. Fouad M, Attia AS, Tawakkol WM, Hashem AM. Emergence of carbapenem-resistant Acinetobacter baumannii harboring the OXA-23 carbapenemase in intensive care units of Egyptian hospitals. Int $J$ Infect Dis. 2013;17(12):e1252-1254. doi:10.1016/j. ijid.2013.07.012

40. Makharita RR, El-Kholy I, Hetta HF, et al. Antibiogram and genetic characterization of carbapenem-resistant Gram-negative pathogens incriminated in healthcare-associated infections. Infect Drug Resist. 2020;13:3991-4002. doi:10.2147/IDR.S276975

41. Nageeb W, Kamel M, Zakaria S, Metwally L. Phenotypic characterization of Acinetobacter baumannii isolates from intensive care units at a tertiary-care hospital in Egypt. East Mediterr Health J. 2014;20 (3):203-211. doi:10.26719/2014.20.3.203

42. Raouf M, Ghazal T, Kassem M, Agamya A, Amer A. Surveillance of surgical-site infections and antimicrobial resistance patterns in a tertiary hospital in Alexandria, Egypt. $J$ Infect Dev Ctries. 2020;14(3):277-283. doi:10.3855/jidc.12124

43. Sultan AM, Seliem WA. Identifying risk factors for healthcare-associated infections caused by carbapenem-resistant acinetobacter baumannii in a neonatal intensive care unit. Sultan Qaboos Univ Med J. 2018;18(1):e75-e80. doi:10.18295/ squmj.2018.18.01.012

44. Basha AM, El-Sherbiny GM, Mabrouk MI. Phenotypic characterization of the Egyptian isolates "extensively drug-resistant Pseudomonas aeruginosa" and detection of their metallo- $\beta$-lactamases encoding genes. Bull Natl Res Cent. 2020;44:117. doi:10.1186/s42269-02000350-8

45. El-Mahdy R, El-Kannishy G. Virulence factors of carbapenem-resistant pseudomonas aeruginosa in hospital-acquired infections in Mansoura, Egypt. Infect Drug Resist. 2019;12:3455-3461. doi:10.2147/IDR.S222329

46. Farhan SM, Ibrahim RA, Mahran KM, Hetta HF, Abd El-Baky RM. Antimicrobial resistance pattern and molecular genetic distribution of metallo-beta-lactamases producing Pseudomonas aeruginosa isolated from hospitals in Minia, Egypt. Infect Drug Resist. 2019;12:2125-2133. doi:10.2147/IDR.S198373

47. Gaballah A, Elbaradei A, Elsheredy A, Kader O. Emergence of blaVEB and blaGES among VIM-producing Pseudomonas aeruginosa clinical isolates in Alexandria, Egypt. Acta Microbiol Immunol Hung. 2019;66(1):131-142. doi:10.1556/030.65.2018.044

48. Hashem H, Hanora A, Abdalla S, Shawky A, Saad A. Carbapenem susceptibility and multidrug-resistance in pseudomonas aeruginosa isolates in Egypt. Jundishapur J Microbiol. 2016;9(11):e30257. doi: $10.5812 / \mathrm{jjm} .30257$

49. Hashem H, Hanora A, Abdalla S, Shaeky A, Saad A. Dissemination of metallo-beta-lactamase in Pseudomonas aeruginosa isolates in Egypt: mutation in blaVIM-4. APMIS. 2017;125(5):499-505. doi:10.1111/apm.12669

50. Khalifa HO, Soliman AM, Ahmed AM, et al. High carbapenem resistance in clinical Gram-negative pathogens isolated in Egypt. Microb Drug Resist. 2017;23(7):838-844. doi:10.1089/ mdr.2015.0339

51. Zafer MM, Al-Agamy MH, El-Mahallawy HA, Amin MA, Ashour MS. Antimicrobial resistance pattern and their beta-lactamase encoding genes among Pseudomonas aeruginosa strains isolated from cancer patients. Biomed Res Int. 2014;2014:101635. doi:10.1155/2014/101635

52. ElMahallawy H, Zafer MM, Amin MA, Ragab MM, Al-Agamy MH. Spread of carbapenem resistant Enterobacteriaceae at tertiary care cancer hospital in Egypt. Infect Dis (Lond). 2018;50(7):560-564. doi:10.1080/23744235.2018.1428824

53. Helal SF, El-Rachidi NG, AbdulRahman EM, Hassan DM. The presence of blaKPC-mediated resistance in Enterobacteriaceae in Cairo University hospitals in Egypt and its correlation with in vitro carbapenem susceptibility. $J$ Chemother. 2014;26(2):125-128. doi:10.1179/1973947813Y.0000000099 
54. Kamel NA, El-Tayeb WN, El-Ansary MR, Mansour MT, Aboshanab KM. Phenotypic screening and molecular characterization of carbapenemase-producing Gram-negative bacilli recovered from febrile neutropenic pediatric cancer patients in Egypt. PLoS One. 2018;13(8):e0202119. doi:10.1371/journal.pone.0202119

55. Tawfick MM, Alshareef WA, Bendary HA, Elmahalawy H, Abdulall AK. The emergence of carbapenemase blaNDM genotype among carbapenem-resistant Enterobacteriaceae isolates from Egyptian cancer patients. Eur J Clin Microbiol Infect Dis. 2020;39 (7):1251-1259. doi:10.1007/s10096-020-03839-2

56. El-Badawy MF, El-Far SW, Althobaiti SS, Abou-Elazm FI, Shohayeb MM. The First Egyptian report showing the co-existence of bla NDM-25, bla OXA-23, bla OXA-181, and bla GES-1 among carbapenem-resistant $\mathrm{K}$. pneumoniae clinical isolates genotyped by BOX-PCR. Infect Drug Resist. 2020;13:1237-1250. doi:10.2147/ IDR.S244064

57. ElMahallawy H, Zafer MM, Al-Agamy M, et al. Dissemination of ST101 blaOXA-48 producing Klebsiella pneumoniae at tertiary care setting. J Infect Dev Ctries. 2018;12(6):422-428. doi:10.3855/ jidc. 9789

58. Ghaith DM, Zafer MM, Said HM, et al. Genetic diversity of carbapenem-resistant Klebsiella Pneumoniae causing neonatal sepsis in intensive care unit, Cairo, Egypt. Eur J Clin Microbiol Infect Dis. 2020;39(3):583-591. doi:10.1007/s10096-019-03761-2

59. Khalil MAF, Elgaml A, El-Mowafy M. Emergence of multidrug-resistant New Delhi Metallo-beta-Lactamase-1-producing klebsiella pneumoniae in Egypt. Microb Drug Resist. 2017;23 (4):480-487. doi:10.1089/mdr.2016.0003

60. Khalil MAF, Hager R, Abd-El Reheem F, et al. A Study of the Virulence Traits of carbapenem-resistant klebsiella pneumoniae Isolates in a Galleria mellonella model. Microb Drug Resist. 2019;25(7):1063-1071. doi:10.1089/mdr.2018.0270

61. Mohamed ER, Ali MY, Waly N, Halby HM, El-Baky RMA. The Inc FII plasmid and its contribution in the transmission of blaNDM-1 and blaKPC-2 in Klebsiella pneumoniae in Egypt. Antibiotics (Basel). 2019;8(4). doi:10.3390/antibiotics8040266

62. Ragheb SM, Tawfick MM, El-Kholy AA, Abdulall AK. Phenotypic and genotypic features of klebsiella pneumoniae harboring carbapenemases in Egypt: OXA-48-like carbapenemases as an investigated model. Antibiotics (Basel). 2020;9(12). doi:10.3390/ antibiotics 9120852

63. Wasfi R, Elkhatib WF, Ashour HM. Molecular typing and virulence analysis of multidrug resistant Klebsiella pneumoniae clinical isolates recovered from Egyptian hospitals. Sci Rep. 2016;6:38929. doi:10.1038/srep38929

64. Abdallah HM, Wintermans BB, Reuland EA, et al. Extendedspectrum beta-lactamase- and carbapenemase-producing enterobacteriaceae isolated from Egyptian patients with suspected blood stream infection. PLoS One. 2015;10(5):e0128120. doi:10.1371/journal pone. 0128120

65. Bouchillon SK, Johnson BM, Hoban DJ, et al. Determining incidence of extended spectrum beta-lactamase producing Enterobacteriaceae, vancomycin-resistant Enterococcus faecium and methicillin-resistant Staphylococcus aureus in 38 centres from 17 countries: the PEARLS study 2001-2002. Int J Antimicrob Agents. 2004;24(2):119-124. doi:10.1016/j.ijantimicag.2004.01.010

66. Fam N, Leflon-Guibout V, Fouad S, et al. CTX-M-15-producing Escherichia coli clinical isolates in Cairo (Egypt), including isolates of clonal complex ST10 and clones ST131, ST73, and ST405 in both community and hospital settings. Microb Drug Resist. 2011;17 (1):67-73. doi:10.1089/mdr.2010.0063

67. Zafer MM, El-Mahallawy HA, Abdulhak A, Amin MA, Al-Agamy $\mathrm{MH}$, Radwan HH. Emergence of colistin resistance in multidrug-resistant Klebsiella pneumoniae and Escherichia coli strains isolated from cancer patients. Ann Clin Microbiol Antimicrob. 2019;18(1):40. doi:10.1186/s12941-019-0339-4
68. Abd-Elmonsef MME, Elsharawy D, Abd-Elsalam AS. Mechanical ventilator as a major cause of infection and drug resistance in intensive care unit. Environ Sci Pollut Res Int. 2018;25(31):30787-30792. doi:10.1007/s11356-017-8613-5

69. Awad HA, Mohamed MH, Badran NF, Mohsen M, Abd-Elrhman AS Multidrug-resistant organisms in neonatal sepsis in two tertiary neonatal ICUs, Egypt. J Egypt Public Health Assoc. 2016;91(1):31-38. doi:10.1097/01.EPX.0000482038.76692.3

70. El-Domany RA, Awadalla OA, Shabana SA, El-Dardir MA, Emara M. Analysis of the correlation between antibiotic resistance patterns and virulence determinants in pathogenic klebsiella pneumoniae isolates from Egypt. Microb Drug Resist. 2020. doi:10.1089/ mdr.2020.0236

71. El-Kholy A, Saied T, Gaber M, et al. Device-associated nosocomial infection rates in intensive care units at Cairo University hospitals: first step toward initiating surveillance programs in a resource-limited country. Am J Infect Control. 2012;40(6):e216-220. doi:10.1016/j. ajic.2011.12.010

72. Galal L, Abdel Aziz NA, Hassan WM. Defining the relationship between phenotypic and genotypic resistance profiles of multidrug-resistant enterobacterial clinical isolates. Adv Exp Med Biol. 2019;1214:9-21.

73. Saied T, Elkholy A, Hafez SF, et al. Antimicrobial resistance in pathogens causing nosocomial bloodstream infections in university hospitals in Egypt. Am J Infect Control. 2011;39(9):e61-65. doi:10.1016/j.ajic.2011.04.009

74. Talaat M, Hafez S, Saied T, Elfeky R, El-Shoubary W, Pimentel G. Surveillance of catheter-associated urinary tract infection in 4 intensive care units at Alexandria university hospitals in Egypt. Am J Infect Control. 2010;38(3):222-228. doi:10.1016/j. ajic.2009.06.011

75. Abd El-Baky RM, Masoud SM, Mohamed DS, et al. Prevalence and some possible mechanisms of colistin resistance among multidrug-resistant and extensively drug-resistant pseudomonas aeruginosa. Infect Drug Resist. 2020;13:323-332. doi:10.2147/IDR. S238811

76. Abdelaziz MO, Bonura C, Aleo A, Fasciana T, Cala C, Mammina C. Cephalosporin resistant Escherichia coli from cancer patients in Cairo, Egypt. Microbiol Immunol. 2013;57(5):391-395. doi:10.1111/ 1348-0421.12046

77. Al-Agamy MHM, El-Din Ashour MS, Wiegand I. First description of CTX-M beta-lactamase-producing clinical Escherichia coli isolates from Egypt. Int $J$ Antimicrob Agents. 2006;27(6):545-548. doi:10.1016/j.ijantimicag.2006.01.007

78. El-Badawy MF, Tawakol WM, Maghrabi IA, Mansy MS, Shohayeb MM, Ashour MS. Iodometric and molecular detection of ESBL production among clinical isolates of E. coli fingerprinted by ERIC-PCR: the First Egyptian Report Declares the Emergence of E. coli O25b-ST131clone Harboring blaGES. Microb Drug Resist. 2017;23(6):703-717. doi:10.1089/ mdr.2016.0181

79. Hassan WM, Hashim A, Domany R. Plasmid mediated quinolone resistance determinants qnr, aac $\left(6^{\prime}\right)$-Ib-cr, and qep in ESBLproducing Escherichia coli clinical isolates from Egypt. Indian $J \quad$ Med Microbiol. 2012;30(4):442-447. doi:10.4103/02550857.103766

80. Abdulall AK, Tawfick MM, El Manakhly AR, El Kholy A. Carbapenem-resistant Gram-negative bacteria associated with catheter-related bloodstream infections in three intensive care units in Egypt. Eur J Clin Microbiol Infect Dis. 2018;37(9):1647-1652. doi:10.1007/s10096-018-3294-7

81. Abouelfetouh A, Torky AS, Aboulmagd E. Phenotypic and genotypic characterization of carbapenem-resistant Acinetobacter baumannii isolates from Egypt. Antimicrob Resist Infect Control. 2019;8:185. doi:10.1186/s13756-019-0611-6 
82. Al-Agamy MH, Khalaf NG, Tawfick MM, Shibl AM, El Kholy A. Molecular characterization of carbapenem-insensitive Acinetobacter baumannii in Egypt. Int $J$ Infect Dis. 2014;22:49-54. doi:10.1016/j. ijid.2013.12.004

83. Alkasaby NM, El Sayed Zaki M. Molecular Study of Acinetobacter baumannii Isolates for Metallo-beta-Lactamases and extended-Spectrum-beta-Lactamases Genes in Intensive Care Unit, Mansoura University Hospital, Egypt. Int $J$ Microbiol. 2017;2017:3925868. doi:10.1155/2017/3925868

84. El Bannah AMS, Nawar NN, Hassan RMM, Salem STB. Molecular epidemiology of carbapenem-resistant acinetobacter baumannii in a Tertiary Care Hospital in Egypt: clonal spread of blaOXA-23. Microb Drug Resist. 2018;24(3):269-277. doi:10.1089/ mdr.2017.0057

85. Abaza AF, El Shazly SA, Selim HSA, Aly GSA. Metallo-BetaLactamase producing pseudomonas aeruginosa in a Healthcare setting in Alexandria, Egypt. Pol J Microbiol. 2017;66(3):297-308. doi:10.5604/01.3001.0010.4855

86. Abbas HA, El-Ganiny AM, Kamel HA. Phenotypic and genotypic detection of antibiotic resistance of Pseudomonas aeruginosa isolated from urinary tract infections. Afr Health Sci. 2018;18(1):11-21. doi:10.4314/ahs.v18i1.3

87. El Zowalaty ME, Gyetvai B. Effectiveness of antipseudomonal antibiotics and mechanisms of multidrug resistance in pseudomonas aeruginosa. Pol $J$ Microbiol. 2016;65(1):23-32. doi:10.5604/ 17331331.1197272

88. El-Domany RA, Emara M, El-Magd MA, Moustafa WH, Abdeltwab NM. Emergence of imipenem-resistant pseudomonas aeruginosa clinical isolates from Egypt Coharboring VIM and IMP carbapenemases. Microb Drug Resist. 2017;23(6):682-686. doi:10.1089/mdr.2016.0234

89. El-Mahdy TS. Expression of ampC, oprD, and mexA, outer membrane protein analysis and carbapenemases in multidrug resistant clinical isolates of Pseudomonas aeruginosa from Egypt. J Chemother. 2014;26(6):379-381. doi:10.1179/ 1973947814Y.0000000195

90. Raouf MR, Sayed M, Rizk HA, Hassuna NA. High incidence of MBL-mediated imipenem resistance among Pseudomonas aeruginosa from surgical site infections in Egypt. J Infect Dev Ctries. 2018;12 (7):520-525. doi:10.3855/jidc.9936
91. Soliman AM, Zarad HO, Nariya H, Shimamoto T, Shimamoto T. Genetic analysis of carbapenemase-producing Gram-negative bacteria isolated from a university teaching hospital in Egypt. Infect Genet Evol. 2020;77:104065. doi:10.1016/j.meegid.2019.104065

92. Zafer MM, Al-Agamy MH, El-Mahallawy HA, Amin MA, El din ashour S. Dissemination of VIM-2 producing Pseudomonas aeruginosa ST233 at tertiary care hospitals in Egypt. BMC Infect Dis. 2015;15:122. doi:10.1186/s12879-015-0861-8

93. Poirel L, Abdelaziz MO, Bernabeu S, Nordmann P. Occurrence of OXA-48 and VIM-1 carbapenemase-producing Enterobacteriaceae in Egypt. Int J Antimicrob Agents. 2013;41(1):90-91. doi:10.1016/j. ijantimicag.2012.08.015

94. El-Kholy AA, Girgis SA, Shetta MAF, Abdel-Hamid DH, Elmanakhly AR. Molecular characterization of multidrug-resistant Gram-negative pathogens in three tertiary hospitals in Cairo, Egypt. Eur J Clin Microbiol Infect Dis. 2020;39(5):987-992. doi:10.1007/ s10096-020-03812-z

95. Helmy OM, Kashef MT. Different phenotypic and molecular mechanisms associated with multidrug resistance in Gram-negative clinical isolates from Egypt. Infect Drug Resist. 2017;10:479-498. doi:10.2147/IDR.S147192

96. Ahmed SH, Daef EA, Badary MS, Mahmoud MA, Abd-Elsayed AA. Nosocomial blood stream infection in intensive care units at Assiut University Hospitals (Upper Egypt) with special reference to extended spectrum beta-lactamase producing organisms. BMC Res Notes. 2009;2:76. doi:10.1186/1756-0500-2-76

97. Azzab MM, El-Sokkary RH, Tawfeek MM, Gebriel MG. Multidrugresistant bacteria among patients with ventilator associated pneumonia in an emergency intensive care unit, Egypt. East Mediterr Health J. 2016;22(12):894-903. doi:10.26719/2016.22.12.894

98. Hassuna NA, AbdelAziz RA, Zakaria A, Abdelhakeem M. Extensively-drug resistant Klebsiella pneumoniae recovered from neonatal sepsis cases from a major NICU in Egypt. Front Microbiol. 2020;11:1375. doi:10.3389/fmicb.2020.01375

99. Metwally L, Gomaa N, Attallah M, Kamel N. High prevalence of Klebsiella pneumoniae carbapenemase-mediated resistance in K. pneumoniae isolates from Egypt. East Mediterr Health J. 2013;19(11):947-952. doi:10.26719/2013.19.11.947
Infection and Drug Resistance

\section{Publish your work in this journal}

Infection and Drug Resistance is an international, peer-reviewed openaccess journal that focuses on the optimal treatment of infection (bacterial, fungal and viral) and the development and institution of preventive strategies to minimize the development and spread of resistance. The journal is specifically concerned with the epidemiology of antibiotic resistance and the mechanisms of resistance development and diffusion in both hospitals and the community. The manuscript management system is completely online and includes a very quick and fair peerreview system, which is all easy to use. Visit http://www.dovepress.com/ testimonials.php to read real quotes from published authors. 